\title{
Yimin Chen
}

\section{University of Western Ontario, London, Ontario, Canada}

\section{Remove me from this list: A case study of trolling in an academic mass email thread (Paper)}

\begin{abstract}
:
This work examines in detail trolling behaviour that occurred during the mass email "reply allpocalypse" of 2019 at a university in southwestern Ontario. Whereas internet trolling is generally thought of as anonymous, antisocial behaviour, this event defies such characterizations in three ways: 1) all respondents participated on a real-name basis, 2) the majority of trolling messages sent were non-malicious attempts at humour, and 3) the email trolling seemed to have at least some pro-social, community-building effects. This study challenges assumptions about who engages in internet trolling and for what purpose by presenting an example of benign trolling in academia.
\end{abstract}

\section{Introduction}

One fall Tuesday morning in 2018, an email message advertising upcoming events and guest speakers at the department of Women's Studies was sent to thousands of students, staff, and professors at a large university in southwestern Ontario. Mass emails such as this are a common occurrence at this institution and many others like it, and this case would not otherwise be notable but for one quirk: instead of using the "blind carbon copy" (BCC) function for the list of recipients, the sender of this email (presumably) accidentally used the regular "carbon copy" (CC) function. This meant that, when the people who were upset that they had received an email not directly and personally relevant to them inevitably wrote back to complain, many of these curmudgeons mistakenly replied-all to the entire list of institutional recipients rather than the initial sender only. These first reply-all missteps prompted others to reply-all, some commenting on the futility of requests to be removed from institutional mailing lists and others attempting to chastise the use of reply-all (while themselves using reply-all to do so). These, in turn, inspired yet more people to chime in, causing the email thread to rapidly snowball.

Over the next two days, this mass email thread spiralled out of control into hundreds of reply-all messages filled with jokes, memes, insults, pleas for decorum, and all manner of trolling behaviour that is, many of the participants in this thread did so in order "to cause disruption and/or to trigger or exacerbate conflict for the purposes of their own amusement" (Hardaker, 2010). The thread was eventually shut down by IT services, but not before spawning several Facebook groups, Twitter conversations, and real-life posters on campus referencing the now-famous "remove me from this list" phrase.

\section{Background}

Cases of email storms are not uncommon and may afflict any organization or group using mailing lists. Notable past occurrences include blow-ups at New York University (Signore, 2012), the UK's National Health Service (Siddique, 2016), the state government of Utah (Turkewitz, 2018), and at Microsoft (Weinberger, 2019). Although there is often some media coverage of these events, research into email communications has been sparse since the mid-2000s. Au and Marks (2013) suggest three reasons why 
email messages may be underused as a source of data: 1) difficulty in establishing proper context when interpreting the variety of types of email messages, 2 ) ethical issues related to the access to and confidentiality of email, and 3) challenges in triangulation between email data and other types of data (e.g. interviews). It may also be the case that email is seen as mundane or old technology. Despite these issues, email studies can provide valuable insight into how people interact in a variety of workplace and organizational settings, such as in education (Maxwell, 2012) and health care (Harvey, et al, 2008).

The case of the Women's Studies "reply allpocalypse" represents a unique opportunity to document emergent trolling behaviour in an under-studied environment: academia. Despite a growing body of literature on internet trolling in the recent years, researchers have, thus far, tended to focus on social media platforms (Cole, 2015; Karppi, 2013), message forums (Coles \& West, 2016), and online video games (Cook, Schaafsma \& Antheunis, 2017). Furthermore, much of this body of work frames trolling as a behaviour tied to anonymity or pseudonymity (Knuttila, 2011; Santana, 2013; Van der Nagel \& Frith, 2015) and motivated by antisocial or psychopathic impulses (Lopes \& Yu, 2017; Synnott, Coulias \& loannou, 2017). The Women's Studies "reply allpocalypse" defies these past characterizations of internet trolling in three ways: 1 ) all respondents participated on a real-name basis either through their institutional or personal email, 2) the majority of trolling messages sent were non-malicious attempts at humour, and 3) the email trolling seemed to have at least some pro-social effects, as conversations within the email thread and over social media made references to how new friendships had formed through this shared experience.

\section{Methods}

This work-in-progress seeks to provide a descriptive analysis of the Women's Studies "reply allpocalypse" from beginning to end. I will map out the timeline of the mass email thread based on email timestamps and trace the various branching conversations as they develop over the course of the email storm. Messages will be coded and classified using thematic analysis (Braun \& Clarke, 2008), and individual participants will be tracked through the thread to determine the extent of their interactions. All personal information associated with the email data will be anonymized and any references to the content of the messages will have identifying information removed. Ultimately, this study will determine the number of participants in this mass email, the form and extent of their participation, and number and types of interactions that occurred.

\section{Conclusion}

This work makes a novel contribution to the field of internet trolling by examining a case that challenges many traditional assumptions about trolling. Trollers in this case were fully identified, rather than anonymous, and from demographics commonly thought of as targets of trolling, rather than perpetrators of it. The event occurred over email, rather than on social media, and was primarily goodnatured, rather than antagonistic. Compared with newer modes of online communications, email correspondence may seem familiar and unexciting, but instances of mass email blow-ups serve as a reminder that there is still much to be learned from the use of even the most established forms of communications technology. 


\section{Reference List:}

Au, Y. W., Marks, A. (2013). Why are social scientists still reluctant to embrace email as data? An ethnographic examination of interactions within virtual teams. Work, Employment and Society, 27(5), 880-890.

Braun, V., \& Clarke, V. (2006). Using thematic analysis in psychology. Qualitative research in psychology, 3(2), 77-101.

Cole, K. K. (2015). "It's like she's eager to be verbally abused": Twitter, trolls, and (en) gendering disciplinary rhetoric. Feminist Media Studies, 15(2), 356-358.

Coles, B. A., \& West, M. (2016). Trolling the trolls: Online forum users constructions of the nature and properties of trolling. Computers in Human Behavior, 60, 233-244.

Cook, C., Schaafsma, J., \& Antheunis, M. (2016). Under the bridge: An in-depth examination of online trolling in the gaming context. New Media \& Society, 20(9), 3323-3340.

Hardaker, C. (2010). Trolling in asynchronous computer-mediated communication: from user discussions to theoretical concepts. Journal of Politeness Research, 6(2), 215-242.

Harvey, K., Churchill, D., Crawford, P., Brown, B., Mullany, L., Macfarlane, A., \& McPherson, A. (2008). Health communication and adolescents: what do their emails tell us? Family Practice, 25(4), 304-311.

Karppi, T. (2013). 'Change name to No One. Like people's status' Facebook Trolling and Managing Online Personas. The Fibreculture Journal, 22.

Knuttila, L. (2011). User unknown: 4chan, anonymity and contingency. First Monday, 16(10).

Lopes, B., \& Yu, H. (2017). Who do you troll and Why: An investigation into the relationship between the Dark Triad Personalities and online trolling behaviours towards popular and less popular Facebook profiles. Computers in Human Behavior, 77, 69-76.

Maxwell, S. V. (2015). Mirror, mirror on the wall: email as an object of practitioner inquiry. Educational Action Research, 23(2), 271-289.

Santana, A. D. (2014). Virtuous or vitriolic: The effect of anonymity on civility in online newspaper reader comment boards. Journalism Practice, 8(1), 18-33.

Siddique, H. (2016, November 14). '186m needless emails': NHS-wide test message (and replies) crash system. The Guardian. Retrieved from https://www.theguardian.com/society/2016/nov/14/186m-needless-emails-nhs-wide-testmessage-and-replies-to-all-crash-system 
Signore, J. (2012, November 28). 40,000 NYU Students United In Annoyance With Discovery Of "Reply-All" Email Feature. Gothamist. Retrieved from http://gothamist.com/2012/11/28/all_40000_nyu_students_united_in_an.php

Synnott, J., Coulias, A., \& Ioannou, M. (2017). Online trolling: The case of Madeleine McCann. Computers in Human Behavior, 71, 70-78.

Turkewitz, J. (2018, December 10). What Happens When You Reply All to 22,000 State Workers. The New York Times. Retrieved from https://www.nytimes.com/2018/12/10/us/reply-all-utah-state-workers.html

Van der Nagel, E., \& Frith, J. (2015). Anonymity, pseudonymity, and the agency of online identity: Examining the social practices of r/Gonewild. First Monday, 20(3).

Weinberger, M. (2019, January 24). As many as 11,543 Microsoft employees got swept up in a reply-all email apocalypse. Business Insider. Retrieved from https://www.businessinsider.com/microsoft-employee-github-reply-all-email-storm$\underline{2019-1}$ 